\title{
Frequency of Fistula formation in the Management of Hypospadias cripples in patients of different age groups by Bracka's Technique
}

\author{
Muhammad Akhtar, ${ }^{1}$ Imran Adeel, ${ }^{2}$ Col. Nadeem Aslam, ${ }^{3}$ Ghazanfar Ali ${ }^{4}$
}

\begin{abstract}
Background: Hypospadias is a congenital anomaly, exclusive to the male population involving male external genitalia. Incidence varies in different populations and ethnic groups.

Objective: To determine the frequency of fistula formation after two staged Bracka's technique in the management of hypospadias cripples in patients of different age groups.

Methodology: Setting: Department of Plastic and Reconstructive Surgery, Shaikh Zayed Hospital, Lahore. Duration of Study: From January 2011 to June 2014. Study Design: Descriptive case series. Sampling Technique: Nonprobability: purposive sampling. Study subjects: Patients with age 1 to 60 years, diagnosed as case of hypospadias cripples diagnosed clinically (patients having a persistent functional complication after initial repair). The data was entered into SPSS version 22 and analyzed through it. Fistula formation was presented as frequencies and percentages.

Results: The mean age was $8.26 \pm 5.67$. The majority of the patients, $71(84 \%)$ were less than 10 years of age, 6 patients (7\%) were between 10-20 years of age, while 8 patients $(9 \%)$ were more than 20 years of age. Only 9 patients $(11 \%)$ had a fistula and most of the patients $76(89 \%)$ had no fistula. There was $1(1 \%)$ patient who had fistula less than 10 years of age, $2(3 \%)$ patients had fistula between 10-20 years of age while $6(7 \%)$ patients had fistula more than 20 years of age.

Conclusion: It is concluded that the early intervention in cases of hypospadias cripples results in lesser complications and lesser functional problems as compared to increasing age at the time of presentation.
\end{abstract}

Keywords: Hypospadias, Fistula formation, Staged Bracka's Technique.

Article Citation: Akhtar M, Adeel I, Aslam N, Ali G. Frequency of Fistula formation in the Management of Hypospadias cripples in patients of different age groups by Bracka's Technique. JSZMC 2021;12(3):08-11. DOI: https://doi.org/10.47883/jszmc.v12i02

This Open Access Article in Journal of Sheikh Zayed Medical College is licensed under a Creative Commons Attribution- 4.0 International License(CC BY 4.0).

\section{Introduction}

Hypospadias is a congenital anomaly. It is an exclusive disease of the male population involving male external genitalia. There is an abnormal opening of the urethra on the ventral aspect of the penis. ${ }^{1}$ The location of the abnormal opening varies from as distal as subglanar to as proximal as perineum depending on the extent of involvement of the urethral plate. Incidence varies in different populations and ethnic groups from as low as 1 in 4000 to as high as 1 in 125 male births. ${ }^{2}$ Multiple procedures have been described for this anomaly depending on the expertise available and the location of the abnormal urethral opening. Broadly these are divided into two main groups; single-stage and two-stage procedures. ${ }^{3}$ Bracka's technique is one of the most commonly used twostaged technique with good functional and aesthetic outcomes. Regarding the timing of surgery, there is no clear-cut protocol in the literature but as for other congenital anomalies involving skin and soft tissue, it is recommended to intervene as early as possible once the child is fit for general anesthesia. ${ }^{4-6}$ The American Academy of Pediatrics recommends repair at an early age of 6-12 months in cases of primary hypospadias. The reason behind the early intervention is two folds. Firstly in infancy and early childhood, tissue elasticity and plasticity are good so results are more predictable. ${ }^{5}$ Secondly there are social stigmas associated with congenital genital problems and low self-esteem. ${ }^{7-9}$ It is therefore always recommended to do such procedures at an early age to avoid social, psychological, and functional problems. The complication rate of surgery varies from patient to patient depending on the severity of disease, the procedure used, the expertise of the operating surgeon, age of the patient, and in patients with hypospadias cripples. ${ }^{10,11}$

There is little data available on the incidence of

1. Department of Urology, Ibn e Siena Hospital, Multan, Pakistan.

2. Department of Plastic Surgery, Ibn e Siena Hospital, Multan, Pakistan.

3. Department of General Surgery, Ibn e Siena Hospital, Multan, Pakistan.

4.Department of Plastic Surgery, CMH, Multan.

Correspondence: Dr. Muhammad Akhtar, Assistant Professor, Department of Urology, Ibn e Siena Hospital Multan, Pakistan.

Email: drakhtarmalik@gmail.com

Received: $15-02-2020$

Published: 21-09-2021 
fistula formation in different age groups. In a study by Gill and Hameed, one aspect was an association of fistula formation in different age groups of patients. ${ }^{8}$ They observed an increased incidence of fistula rate with increasing age. ${ }^{12-14}$ In our study we want to see the actual incidence of fistula formation in the management of hypospadias cripples in patients of different age groups to confirm our clinical findings and to propose a treatment protocol regarding the timing of surgery. ${ }^{15-17}$ The objective of this study was to determine the frequency of fistula formation after two staged Bracka's technique for hypospadias cripples management.

\section{Methodology}

Study Design: This was a descriptive case series. Setting: This study was conducted at the Department of Plastic and Reconstructive Surgery, Shaikh Zayed Postgraduate Medical Institute, Lahore. Duration of Study: From January 2011 to June 2014. Sampling Technique: Non-probability, consecutive sampling. Sample Size: Sample size of 85 cases is calculated with $95 \%$ confidence level, $10 \%$ margin of error, and taking an expected percentage of fistula formation i.e. $33 \%$ after Bracka's technique for hypospadias cripples. Study subjects: Patients with age 1 to 60 years, diagnosed as a case of hypospadias cripples diagnosed clinically (patients having a persistent functional complication after initial repair). Exclusion Criteria: Patients with a history of primary hypospadias in which no previous surgery has been performed for hypospadias management and hypospadias associated with any congenital syndrome assessed clinically.

The data was entered into SPSS version 22 and analyzed through it. The variables were presented as simple descriptive statistics giving mean and standard deviation for numerical data like age. Fistula formation was presented as frequencies and percentages. Data was stratified for age. The Chi-square test was applied post-stratification with $\mathrm{p}$-value $<0.05$ considered as significant.

\section{Results}

This study was carried out on a total of eighty-five patients and patients were included by convenient sampling. The age range of patients was 3-30 years. The mean age was $8.2 \pm 5.6$ years. Table-I shows the patients were divided into three age groups; patients with age less than 10 years, patients between 10-20 years, and age more than 20 years. A major proportion $71(84 \%)$ of patients were less than 10 years of age, 6 patients ( $7 \%$ ) between $10-20$ years of age, while $8(9 \%)$ patients were more than 20 years of age. Figure-I shows the frequency of fistula in patients. Only 9 patients $(11 \%)$ had fistula while the majority of the patients $76(89 \%)$ healed without fistula formation.

Table-II shows the stratification of fistula according to the age of patients. Out of 9 patients, one (1\%) patient was less than 10 years of age, $2(3 \%)$ patients were between $10-20$ years of age and $6(7 \%)$ patients were older than 20 years of age.

$(\mathrm{P}$ value $=0.000)$

Table-I: Age Distribution of Patients $(\mathrm{n}=\mathbf{8 5})$

\begin{tabular}{|c|c|c|}
\hline Age in years & No. of Patients & Percentage \\
\hline$<10$ & 71 & 84 \\
\hline $10-20$ & 6 & 7 \\
\hline$>20$ & 8 & 9 \\
\hline Mean \pm SD & \multicolumn{2}{|c|}{$8.26 \pm 5.67$} \\
\hline
\end{tabular}

Figure-I: Frequency of Fistula in Patients

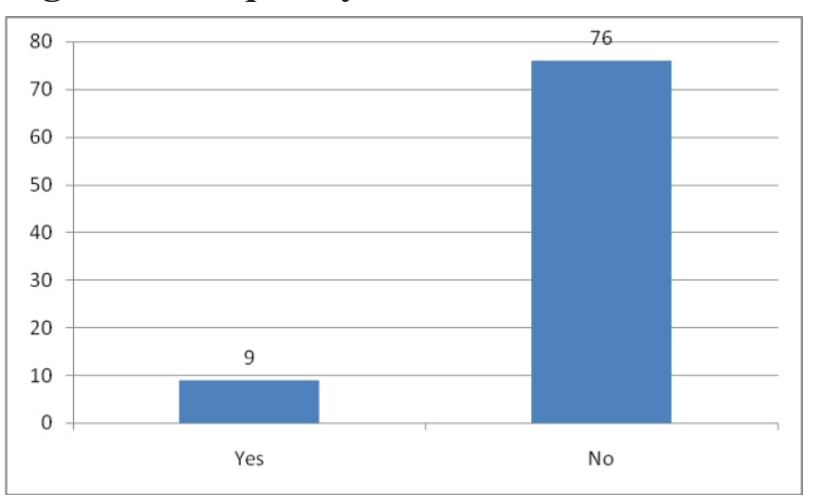

Table-II: Stratification of Fistula According to Age of Patients

\begin{tabular}{|c|c|c|c|}
\hline Age in years & Yes & No & P-value \\
\hline$<10$ & $1(1 \%)$ & $61(72 \%)$ & \multirow{2}{*}{0.000} \\
\cline { 1 - 3 } $10-20$ & $2(3 \%)$ & $14(16 \%)$ & \\
\cline { 1 - 3 }$>20$ & $6(7 \%)$ & $1(1 \%)$ & \\
\hline
\end{tabular}




\section{Discussion}

Failed hypospadias is managed by multiple types of surgical techniques over many previous decades, and in such patients, many revision surgeries need to be conducted. ${ }^{17}$ Patients after many attempted surgeries still face many problems including functional and/or cosmetic complications, which usually result in a penis with little tissue, scarring, and are unusable. ${ }^{18}$ Despite having an experienced hand of surgeon during reconstruction surgery there are chances of failure. The evidence shows that a ventral incision in the already scarred urethra will cause the area susceptible to fistulas and/or breakdown of the free graft. ${ }^{19}$

The hypospadias is a congenital abnormality of the male external genitalia, occurring in one out of 300 live births. Before 1980, hypospadias repair was performed in children older than 3 years because of the larger size of the phallus and a technically easier procedure; however, genital surgery at this age (genital awareness occurs at about age 18 months) can be associated with significant psychological morbidity, including abnormal behavior, guilt, and gender identity confusion. ${ }^{18,19}$ Currently, most surgeons attempt to repair hypospadias when the child is aged 4-18 months, trending toward earlier intervention. American Association of Pediatrics suggests 6-12 months of age for the repair of primary hypospadias. This has been associated with an improved emotional and psychological results. A benefit in wound healing with earlier repair has also been perceived and may have a basis in the reduced pro-inflammatory cytokine production noted at a younger age.' The late hypospadias repair, in the pubertal and postpubertal period, is associated with complications, primarily urethrocutaneous fistula, in nearly half of patients. More recent reports suggest a higher rate of complication in 5-year-old patients than in 1-yearold patients, suggesting that earlier repair is generally better. ${ }^{20-22}$ In a study by Ziada $\mathrm{A}$, they assess the outcome of hypospadias repair in older children. they have complications in only 6 out of $61(9.8 \%)$ patients and all were from groups 2 and 3 (age range from 2 to more than 4 years. ${ }^{3}$

In another study, ${ }^{4}$ it was assessed that the outcomes of delayed hypospadias repair with a complication rate of $48 \%$ in older age at the time of primary hypospadias repair. In a study by Gill and Hameed in 100 patients with hypospadias cripples, one aspect of the study was the age at the time of surgery. They found a significantly higher complication rates with increasing age as compared to early intervention. ${ }^{1}$ In our study, the age range of patients was 3-30 years. The mean and standard deviation was $8.26 \pm 5.67$. we divided the patients into three different age groups. Group 1 includes patients with ages less than 10 years, group 2 with patients between 10-20 years, and group 3 with patients more than 20 years of age. A major proportion $71(84 \%)$ of patients were less than 10 years of age, 7 patients $(8 \%)$ were between $10-20$ years of age, while there were also 7 (8\%) patients more than 20 years of age. In the present study, the overall fistula rate is $11 \%$. There was $1(1 \%)$ patient had fistula less than 10 years of age, $2(3 \%)$ patients had fistula between 10 20 years of age while $6(7 \%)$ patients had fistula more than 20 years of age. The above-mentioned results clearly highlight the importance of hypospadias cripples treatment at an early age to improve the results and minimize the complications, and this is supported by the previous literature as well. ${ }^{23-26}$

\section{Conclusion}

Our study clearly highlights the importance of hypospadias cripples treatment at an early age to improve the outcome and minimize functional and psychological problems. It is therefore recommended that the surgery for hypospadias cripples should be carried out at an early age to improve outcomes and to avoid social and psychological problems associated with this anomaly. Further studies at larger scales are required to support our findings and to devise a treatment protocol for the patients of hypospadias cripples.

Authors Contribution: MA: Design of work, Acquisition and analysis of data and Drafting. IA: Conception of work and Revising. NA: Interpretation of data and drafting. GA: Conception of work and drafting.

All authors critically revised and approve its final version.

Conflict of Interest: Author has declared no conflict of interest.

Sources of Funding: The source of funding was self. Disclaimer: None 


\section{References}

1. Gill NA, Hameed A. Management of hypospadias cripples with two-staged Bracka's technique. J Plast Reconstr Aesthetic Surg. 2011;64:91-6.

2. Horton CA. Reconstruction of genitourinary anomalies. Hypospadias. In: Achauer BM, ed. Plastic Surgery: indications, operations and outcome. $1^{\text {st }}$ Mosi, Inc; 2000. p 533-37.

3. Ziada A. Outcome of hypospadias repair in older children: a prospective study. J Urol. 2011;185(6 suppl):2486; author reply 2486.

4. Dodson JL. Outcomes of delayed hypospadias repair: implications for decision making. J Urol. 2007 Jul;178(1):278-81

5. Bracka A. The role of two-stage repair in modern hypospadialogy. Indian J Urol. 2008;24:210-8.

6. Rashed FK, Javid S. Hypospadias repair in adults, a comparison with children. Int J Urol. 2012;9:3.

7. Shaikh BF, Memon AR, Kumar SM. Hypospadias repair an experience at a tertiary care hospital. Med Channel 2010;16:326-27.

8. Smith ED.The history of hypospadias. Pediatr Surg Int. 1997;12:81-5.

9. Sebastian K, Spencer B. Surgical conditions in older children. In: Mike S. Practical Paediatrics, $7^{\text {th }}$ ed. Churchill Livingstone, Elsevier. p. 1986; 266-67.

10. Porter MP, Faizan MK, Grady RW, Mueller BA. Hypospadias in Washington State: maternal risk factors and prevalence trends. Pediatrics. 2005; 115: 495-99.

11. Kallen B, Bertollini R, Castilla E. A joint international study on the epidemiology of hypospadias. Acta Paediatr Scand Suppl. 1986;324:1-52.

12. Fabio S, Jorge IT. Penile hypospadias reconstruction. 2014 . Ava i a b l e from : https://emedicine.medscape.com/article/ 1297569overview

13. Prabudh G, Minu B, Ajay V. Recent advances in hypospadias. JIMSA. 2014; 27: 95-100.

14. King S, Beasley S. Surgical conditions in older children. In: South M. Practical Paediatrics, Seventh edition. Churchill Livingstone, Elsevier. 2012; pp. 266-67.

15. Silver RI, Russell DW. Five alpha-reductase type 2 mutations are present in some boys with isolated hypospadias. J Urol. 1999; 162: 1142-5.
16. Gershbaum MD, Stock JA, Hanna MK. A case for the 2stage repair of perineoscrotal hypospadias with severe chordee. J Urol. 2002;168:1727-8.

17. Nitkunan T, Johal NS, O'malley K, Cuckow PM. Secondary hypospadias repair in two stages. J Pediatr Urol. 2006; 2: $559-63$.

18. Stein R, Schroder A, Thuroff JW. Surgical atlas: Primary hypospadias repair with buccal mucosa. BJU Int. 2006; 97 : 871-89.

19. Wood DN, Allen SE, Andrich DE, Greenwell TJ, Mundy AR. The morbidity of buccal mucosal graft harvest for urethroplasty and the effect of nonclosure of the graft harvest site on postoperative pain. J Urol. 2004;

20.172:580-3.21. Bracka A. A versatile two-stage hypospadias repair. Br J Plast Surg 1995; 48:345-52.

21. Telfer JR, Quaba AA, Kwai Ben I, Peddi NC. An investigation into the role of waterproofing in a two-stage hypospadias repair. Br J Plast Surg. 1998; 51:542-6.

22. Lee OT, Durbin-Johnson B, Kurzrock EA. Predictors of Secondary Surgery after Hypospadias Repair: A populationbased analysis of 5,000 patients. J Urol. 2013; 190(1):251-5. doi: 10.1016/j.juro.2013.01.091.

23. Yildiz T, Tahtali IN, Ates DC, Keles I, Ilce Z. Age of patient is a risk factor for urethrocutaneous fistula in hypospadias surgery. J Pediatr Urol. 2013; 9(6 Pt A):900-3. doi: 10.1016/j.jpurol.2012.12.007.

24. Chung JW, Choi SH, Kim BS, Chung SK. Risk factors for the development of urethrocutaneous fistula after hypospadias repair: a retrospective study. Korean J Urol. 2012; 53:711-5.

25. Chertin B, Natsheh A, Ben-Zion I, Prat D, Kocherov S, Farkas A. temporary removal: Objective and subjective sexual outcomes of adult patients following hypospadias repair performed in childhood. J Urol. 2013;8-15

26. Shahzad I, Ali S, Fasih-Ud-Din Q. Outcome of Urethro Cutaneous Fistula Repair. Pak J Med Sci 2011; 27(3):574577 